\title{
The Role of Self-efficacy on Performance of Sports Skills of Football Players
}

\author{
M. Haluk Sivrikaya \\ Correspondence: M. Haluk Sivrikaya, Faculty of Sport Sciences, Ataturk University, Erzurum, Turkey.
}

Received: December 16, 2018

Accepted: January 2, 2019 Online Published: January 7, 2019

doi:10.11114/jets.v6i12a.3952

URL: https://doi.org/10.11114/jets.v6i12a.3952

\begin{abstract}
The main goal of this study was to determine effect of self-efficacy on performance of football players in Erzurum city. The present research was practical in terms of purpose and correlation in term of its nature. The statistical population of research was Ataturk University boys students (18-22 yrs old) unfamiliar to football scissors kick, in 2018. So, 52 participants were selected randomly based on Morgan Table from 60 volunteers. In this study, two questionnaires of self-efficacy and Charbonneau sport performance were used to collect data. To test hypotheses, regression test was used. In this research, SPSS 20 software was used in all calculations and tests. The results showed that self-efficacy play a significant role in learning of scissors kick. Self-efficacy is one of the most important characteristics of a successful athlete.
\end{abstract}

Keywords: athletic skills, self-efficacy, scissors kick

\section{Introduction}

In the last few decades, sport psychology has become an important part of sport, as well-informed and experienced before the competition and during training and exercises try to achieve a level of self-confidence, self-efficacy and measure relevance of these factors to the athlete's success and failure. One of the applications of psychology in sport is to help improve performance, to learn and to execute more correctly and more easily the skills, using different techniques such as mental training, self-confidence and self-efficacy. Admittedly, these psychosocial skills are the main and most prominent components of continuous performance at high levels of competition (Newland et al., 2013).

In professional sport, increasing demands for victory and high-level goals are among the prevalent reasons that lead to psychological stress. Stress is one of the factors that affects the behavior and performance of the athlete. The inability to work effectively with sports stress is detrimental to the athlete's performance (Stoeber, 2001). However, it seems that the effect of stress on performance depends on individual athletes' differences, because some players or coaches manage and manage more stressful and difficult situations than others.

Another factor that contributes to the success of sports psychology is self-efficacy. Self-efficacy means sense of competence, adequacy and ability to cope with life, along with the term self-efficacy, is defined by the individual's belief in ability to perform a successful practical operation to achieve a definite result in case of athletes' self-efficacy. This is an important issue. Athlete's self-efficacy on one hand is influenced by variables such as mastery, ability, physical and mental fitness, physical appearance, social support, leadership and coaching, substitute experiences, environmental comfort, and situational superiority. On the other hand, factors such as performance, success, physical health, ability to cope with stress and minimize its harmful effects, mental health, improve motivation, increase morale and even enjoyment are directly and even indirectly affected by self-efficacy. In the theoretical framework presented by Bandura, one of the factors that may be influenced by self-efficacy is pleasure. Pleasure as a positive emotional response to an exercise experience generally reflects emotions such as pleasure and entertainment (Bandura, 1993).

Eris (2018) studied elite male trampolinists' performance based on the selected psychological capabilities. Findings of study suggested that, in the high competitive level of trampoline, psychological factors (i.e., self-confidence and concentration recovery) have more predictive role which must be considered in preparation programs of elite male trampolinists.

Ercis (2018) studied mental skills of elite and non-elite athletes. He found self-confidence of elite athletes is so higher than non-elite athletes. 
Rasmusen (2016) conducted a research on the effect of mediator of sport self-efficacy on the relationship between perfectionism and competitive anxiety. The results showed that attempts to complete (positive perfectionism) with cognitive and physical anxiety of athletes were negative and trustworthy. They have a positive correlation. Negative reaction to incompleteness (negative perfectionism), on the contrary, was positively correlated with cognitive and physical anxiety of athletes and their self-confidence. Analysis of these results showed that sport self-efficacy has a mediator effect on the relationship between the positive and negative dimensions of perfectionism with competitive anxiety.

Skills to challenge the correct performance are called technique. Skill is one of the most controversial topics in the field of exercise and sports science. Human beings in the 21st century, in contrast to the past century, have more than ever been governed by their own virtues and the environment due to the advancement of technology, all of which, of course, owe the task of teaching and exercising different skills. Undoubtedly, the importance of implementing skills in human development is far beyond the perspective of his thoughts. Therefore, since the environment of human life is always subject to change, man has to perform skills to overcome these transformations. In this discussion, we will talk about the skills in the field of movement science and sports. Skill is one of the most controversial topics in the field of exercise and science of sport (Ucan, 2018).

Research has shown that sport has a close relationship with mental health, especially the prevention of psychological anomalies. In fact, sport is important in many aspects of social, cultural, political, economic and health. In the last few decades, sports psychology has become an important part of sport, especially as coaches are well-known and experienced before the time of the competition and during training and exercises, are athletes and try to achieve a level of self-confidence And self-efficacy and measure the association of these factors with the athlete's success and failure. One of the applications of psychology in sport is to help improve performance, to learn and to execute more correctly and more easily the skills, using various techniques and techniques such as mental training, self-esteem and self-efficacy. Admittedly, these psychosocial skills are the main and most prominent components of ongoing performance at high levels of competition. Today, the importance of the role instructors in the success or failure of sports teams is not unobtainable. This position is double when talking about national games and international credibility.

Sheard (2005) reported that the average self-efficacy increased linearly with the experience of being in a blow-up position. They showed that an important method for self-efficacy as a theory is to study the relationship between efficiency and performance in athletic sports activities. From this point of view, the performance of the individual depends on his/her concentration, persistence and beliefs.

Moritz et al. (2000) saw higher correlations in studies that evaluated postoperative self-efficacy compared to pre-performance self-efficacy. In all of multivariate and multivariable mediator analysis, adaptation between self-efficacy and performance measures was the most important variable. According to Marits and colleagues (2000), there are other variables that may affect the relationship between self-efficacy and performance.

Singh et al. (2009) showed that School National Level athletes were significantly better on perceived physical ability and self-efficacy than the School District Level athletes.

Pinquart (2009) conducted a case study of group efficiency during a season of basketball faculty competitions. He acknowledged that in an affiliated team sport (like basketball), it seems that the status of other opponents (in terms of strength and ability) is also an important element of effective information. He competed with good, moderate, weak and very good opponents to assess the team's confidence when they competed, and found that when the team competed with a weak team, it is most confident and, when competing with the strong team, the lowest feeling has confidence. Finally, He suggested that other topics such as the results of the past two teams, the level of individual skill, team skill level, team history, dynamic and practice time could be applied in the research.

A study by Valiante and Morris (2013) supported Bandura's assertions about mastery experiences being an important self-efficacy source. They asked players to outline their careers, including their successes, their failures, and how these successes and failures affected their subsequent thinking patterns, expected outcomes and emotional states. Valiante and Morris found that professional golfers were able to maintain high self-efficacy over a long time period by recalling their previous successes. This is important as these athletes reported that their self-efficacy beliefs lead to mind-sets that enabled them to be calm and more productive than they would have been, which then enabled them to perform better. This suggests that mastery experiences are an important consideration in professional athletes as these can be beneficial to future performance and that these effects can be influential over a long time frame. Given that the participants in this study are professional athletes, we would then expect mastery experiences (i.e. past performance) to be influential. Therefore, these results suggest that rugby players' self-efficacy after a game should correlate positively with performance within the game.

Ramezani Nejad et al. (2016) examined the relationship between group efficiency, team cohesion and team performance in professional volleyball teams. The findings showed that successful teams tended to have more coherence in assignment than less successful and unsuccessful teams. The results revealed that group efficiency had a positive 
correlation with team performance. Successful athletes were more efficient in a group of less successful teams.

Lin et al. (2017) studied the self-efficacy of young educators and athletes. The findings indicated that the students' self-efficacy was not significantly affected by self-efficacy of the students, but had a positive and significant effect of self-efficacy of the students.

Given the above, is it a question of how self-efficacy and psychological hardiness play a role in the performance of the sports skills of the Erzurum footballers?

\section{Method}

In terms of purpose, the view was implemented as a descriptive (correlation) research. Two methods were used to analyze the information. For analyzing the research data, regression correlation analysis was used for inferential statistics.

\subsection{Society and Sampling Method}

The statistical population of the study was all Ataturk University boy students who vulenteerly participated in this study in number of 60 in 2018. By Morgan table 52 of them were randomly selected for this research.

\subsection{Collection Tool}

General Adult Inventory: This questionnaire was adapted from Schwartz, Ger and Salem (1982). In this research reliability of questionnaire on the basis of Cronbach's alpha was between 1.75 and 1.91 .

\subsection{Charbonneau Sports Performance Questionnaire}

The questionnaire was made in 2001 by Charbonneau. The questionnaire has five questions in the Likert scale and is designed to evaluate the performance of the athletes and is completed by the respective instructor for each athlete. The scores derived from the five questions show the final scores of the athlete's performance. This question is on a scale from 1 (very poorly) to 5 (very special) (Charbunio, Barbing and Kilwa, 2001). The scores derived from the five questions are summarized and the final score of the athlete's performance is obtained, which is the final score of the performance The athlete is in the range of 5 to 25 (at least up to the maximum), and the average of the reliability coefficients of this questionnaire is calculated by Cronboch, 0.71 .

\subsection{Data Analysis Method}

In order to analyze the data obtained from the collected questionnaires, parametric tests such as regression were used. In this research, 20SPSS software has been used in all calculations and reliability of hypothesis testing.

\section{Results}

Frequency distribution and percentage of statistical sample are based on the age of the participants in Table 1 .

Table 1. Frequency distribution age of participants

\begin{tabular}{lcc}
\hline Age & F & Percent \\
\hline $18-20$ & 36 & 69 \\
\hline $21-24$ & 16 & 31 \\
\hline Total & 52 & 100 \\
\hline
\end{tabular}

As shown in Table 1, 164 participants were between 18-20 years old have 70 were 21-24 years old.

Table 2. Correlation between self-efficacy and skill performance

\begin{tabular}{cccc}
\hline & & Self-efficacy & Skill performance \\
\hline Self-efficacy & Pearson correlation coefficient & \\
\hline 2-way significance level (sig) & 0.01 & 0.221 \\
\hline $\mathrm{N}$ & 52 & \\
\hline Skill performance & Pearson correlation coefficient & & \\
\hline & 2-way significance level (sig) & 0.221 & 0.01 \\
\hline $\mathrm{N}$ & 52 &
\end{tabular}

As shown in Table 2, the significance level of the Pearson test was 0.014 and this level was smaller than the minimum level of 0.05 and also calculated according to the Pearson correlation coefficient of 0.221 , So self-efficacy affects the performance of the sports skills of the footballers of Erzurum. 
Table 3. Analysis of variance of self-efficacy regression model on skill performance

\begin{tabular}{ccccccl}
\hline Stand error & & $\begin{array}{c}\text { detection } \\
\text { factor } \\
\text { justified } \Delta \mathrm{R}\end{array}$ & & $\begin{array}{c}\text { Detection coefficient } \\
\left(\mathrm{R}^{2}\right)\end{array}$ & $\mathrm{R}$ & \\
\hline 14.9921 & 0.027 & $\mathrm{MS}$ & $\mathrm{SS}$ & $\mathrm{df}$ & $\begin{array}{l}\text { source of the } \\
\text { changes }\end{array}$ \\
\hline Sig. & $\begin{array}{c}\text { level of } \\
\text { confidence }\end{array}$ & $\mathrm{F}$ & & & 0.035 & 0.192 \\
\hline 0.005 & 0.95 & & 1895.345 & 1895.345 & 1 & Regression \\
\cline { 5 - 8 } $\begin{array}{c}\text { Result } \\
\text { Acceptance }\end{array}$ & 8.11 & 234.567 & 55468.564 & 51 & Rest \\
\hline
\end{tabular}

As it is seen in Table 3 that the significance level of the corresponding test is equal to 0.055 , it can be argued that the above test with a 0.05 error or a confidence level of 0.95 is significant. According to the $\mathrm{R}^{2}$ detection coefficient, which is the ratio of the changes explained by the $\mathrm{x}$ variable to the total changes, is 0.035 . It can be argued that $3.3 \%$ of changes in performance of sport skills are explained by changes in automatic income.

\section{Discussion and Conclusion}

The results of the study showed that self-efficacy has a positive and significant effect on the performance of professional sports players in Erzurum. These results are consistent with the findings of the study by Eris (2018), Lin et al. (2016). Eris (2018) showed that self-efficacy of coaches has a positive and significant effect on athletes self-efficacy. In explaining this, it can be said that Bandura (1990) defined self-efficacy as a sense of confidence in the individual's ability to perform a given behavior in a variety of contexts. Regardless of the interaction between different factors in the emergence of a particular behavior, it is probably the most important factor in the individual's belief in the ability to do that (Sheard, 2010). According to Lin et al. (2017), having a general self-interest always helps the individual to succeed. Having overall self-confidence at a glance, is being able to react positively to situations, ignoring disruptive factors, calming down, and maintaining calm under pressure.

Self-efficacy is the belief in one's capabilities to organize information and execute a course of action to navigate a prospective situation. According to social psychologist Albert Bandura, self-efficacy is a key component of the self-system, which consists of an individual's attitudes, abilities, and cognitive resources. High self-efficacy increases the likelihood of successfully achieving a given task (Bandura, 1982).

Valiante and Morris (2013) found that professional golfers were able to maintain high self-efficacy over a long time period by recalling their previous successes.

Feltz et al. (2008) have suggested that self-efficacy influences goal setting through creating discrepancies between goals and outcomes. When performance standards do not meet the goals an individual sets out, they will react with dissatisfaction. If the discrepancy is not too large, and the individual has high self-efficacy for the task, then the dissatisfaction from a failed goal should be an incentive to expend more effort in order to meet the goal.

Bandura (2012) also suggests that those who have reasonably accurate impressions of their ability will set reasonable, yet challenging goals for themselves. As their competence increases, they will then be motivated to set more challenging goals. However, those who judge their ability as being lower than it is miss out on the potential benefits that come with the activities that they avoid participating in, and fail to develop in this area.

Self-efficacy affects every area of human endeavor. By determining the beliefs a person holds regarding his or her power to affect situations, it strongly influences both the power a person actually has to face challenges competently and the choices a person is most likely to make. These effects are particularly apparent, and compelling, with regard to behaviors affecting health (Luszczynska \& Schwarzer, 2005). Overall, self-efficacy is positively and strongly related to work-related performance (Stajkovic \& Luthans, 1998).

\section{References}

Bandura, A. (1986). Social foundations of thought and action: A social cognitive theory. Englewood Cliffs, NJ: Prentice-Hall.

Bandura, A. (1990). Perceived self-efficacy in the exercise of personal agency. Journal of Applied Sport Psychology, 2, 128-163. https://doi.org/10.1080/10413209008406426

Bandura, A. (1993). Perceived self-efficacy in cognitive development and functioning. Educational Psychologist, 28(2), 117-148. https://doi.org/10.1207/s15326985ep2802_3 
Bandura, A. (2012). On the functional properties of perceived self-efficacy revisited. Journal of Management, 38, 9-44. https://doi.org/10.1177/0149206311410606

Ercis, S. (2018). Mental Skills of Elite and no-elite Athletes, Journal of Educational and Training Studies, 6(4a), 72-75. https://doi.org/10.11114/jets.v6i4a.3425

Erciş, S. (2018). Prediction of elite male trampolinists' performance based on the selected psychological capabilities, Journal of Educational and Training Studies, 6(4a), 19-24. https://doi.org/10.11114/jets.v6i4a.3210

Feltz, D. L., Chow, G. M., \& Hepler, T. J. (2008). Path analysis of self-efficacy and performance: Revisited. Journal of Sport and Exercise Psychology, 28, 401-411. https://doi.org/10.1123/jsep.30.3.401

Lin, Y., Mutz, J., Clough, P. J., \& Papageorgiou, K. A. (2017). Mental Toughness and individual differences in learning, educational and work performance, psychological well-being, and personality: A systematic review. Frontiers in Psychology. https://doi.org/10.3389/fpsyg.2017.01345

Luszczynska, A., \& Schwarzer, R. (2005). Social cognitive theory. In M. Conner \& P. Norman. Predicting health behaviour (2nd ed. rev. ed.). Buckingham, England: Open University Press. 127-169.

Moritz, S. E., Feltz, D. L., Fahrbach, K. R., \& Mack, D. E. (2000). The relation of self-efficacy measures to sport performance: A meta-analytic review. Research Quarterly for Exercise and Sport, 71, 280-294. https://doi.org/10.1080/02701367.2000.10608908

Newland, A., Newton, M., Finch, L., Harbke, C. R., \& Podlog, L. (2013). Moderating variables in the relationship between mental toughness and performance in basketball. Journal of Sport and Health Science, 2(3), 184-192. https://doi.org/10.1016/j.jshs.2012.09.002

Pinquart, M. (2009). Moderating effect of dispositional resilience on association between hassles and psychological distress. Journal of Applied Developmental Psychology, 30, 1-8. https://doi.org/10.1016/j.appdev.2008.10.005

Ramezani, N. R., Panahi, M., \& Reyhani, M. (2011). Comparison of Stress Coping Strategies in Individual Individual Athletes of Iranian National Teams. Olympics Quarterly, 2, 169-155.

Rasmusen, R. (2016). Tackling the Relationship between Self-Efficacy and Performance in Rugby, Master of Science in Applied Psychology, University of Canterbury.

Sheard, M. (2010). Mental toughness the mindset behind sporting achievement, New York. Routledge.

Singh, T. D., Bhardwaj, G., \& Bhardwaj, V. (2009). Effect of Self-Efficacy on the Performance of Athletes, Journal of Exercise Science and Physiotherapy, 5(2), 110-114.

Stajkovic, A. D., \& Luthans, F. (1998). Self-efficacy and work-related performance: A meta-analysis, Psychological Bulletin, 2: 240-261. https://doi.org/10.1037/0033-2909.124.2.240

Stoeber, J., Hutchfield, J., \& Wood, K.V. (2008). Perfectionism, self-efficacy, and aspiration level: Differential effects of perfectionistic striving and self-criticism after success and failure Personality and Individual Differences, 45(4), 323-327. https://doi.org/10.1016/j.paid.2008.04.021

Uçan, I. (2018). The Performance of Prediction of Elite Male Trompline Based on Physical factors, Journal of Educational and Training Studies, 6(4a), 39-44. https://doi.org/10.11114/jets.v6i4a.3259

Valiante, G., \& Morris, D. B. (2013). The sources and maintenance of professional golfers' self-efficacy beliefs. Sport Psychologist, 27, 130-142. https://doi.org/10.1123/tsp.27.2.130

\section{Copyrights}

Copyright for this article is retained by the author(s), with first publication rights granted to the journal.

This is an open-access article distributed under the terms and conditions of the Creative Commons Attribution license which permits unrestricted use, distribution, and reproduction in any medium, provided the original work is properly cited. 